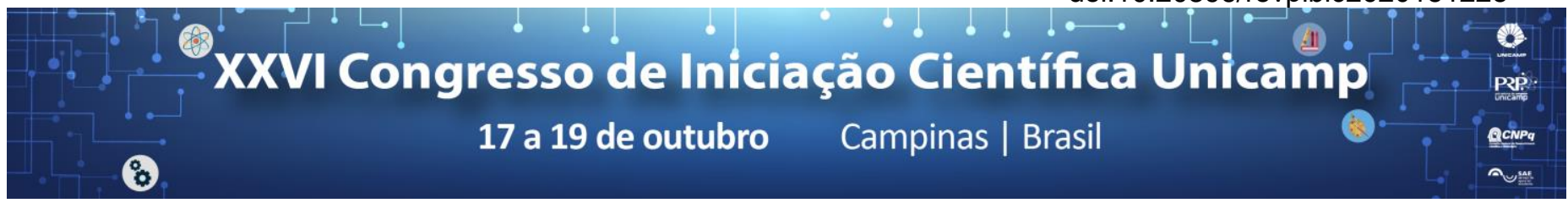

\title{
Avaliação dos níveis de resiliência, empatia e rendimento escolar dos alunos da FOP ao longo do curso de graduação.
}

\section{Rodrigo Vidal de Lima*, Karine Laura Cortellazzi Mendes, Fábio Luiz Mialhe.}

\section{Resumo}

No presente estudo objetivou-se avaliar as variáveis associadas ao rendimento escolar de acadêmicos do curso de odontologia, bem como os níveis de empatia que os alunos de cada ano do curso apresentam. Foram coletados dados de 212 estudantes das cinco turmas por meio de três questionários, sendo eles um sociodemográfico, uma escala de resiliência e uma de empatia. Observou-se que o rendimento escolar esteve associado a variáveis sociodemográficas e psicológicas, e que os graduandos apresentaram diferentes escores de empatia de acordo com o ano de graduação.

\section{Palavras-chave:}

Educação em odontologia, empatia, resiliência psicológica

\section{Introdução}

O ingresso no Ensino Superior é marcado por um período de vulnerabilidade, pois os estudantes são submetidos no espaço universitário a uma considerável carga de estresse. Neste contexto, o desempenho acadêmico pode ser influenciado por diversas variáveis, tais como o nível de resiliência pessoal e empatia dos estudantes. Tendo isso em vista, o presente estudo teve como objetivos 1. Variáveis associadas ao rendimento escolar de acadêmicos do curso de odontologia da FOPUNICAMP e 2. Níveis de empatia que os alunos de cada ano do curso apresentam, objetivando analisar se há diferenças entre os escores gerais de cada uma das turmas.

\section{Resultados e Discussão}

Em se tratando da avaliação das variáveis associadas ao rendimento escolar dos acadêmicos, foram realizadas análises brutas e ajustadas para testar a associação entre a variável dependente (auto percepção do rendimento escolar) e as independentes. As variáveis que apresentaram $p<0,20$ nas análises brutas foram testadas no modelo de regressão logística múltiplo, tendo como critério de permanência no modelo final $p \leq 0,05$. Os testes estatísticos foram realizados pelo programa estatístico SAS.

Com relação à análise dos níveis de empatia apresentados pelos estudantes, foi rodado o teste de não paramétrico de Kruskal Wallis para avaliar diferenças entre as médias do escore do questionário de empatia entre os anos. Entretanto, não foi observada diferença estatística significativa da empatia entre os anos.

Os escores gerais médio por turma estão ilustrados no gráfico 1.

Gráfico 1. Escore geral médio de empatia por turmas.

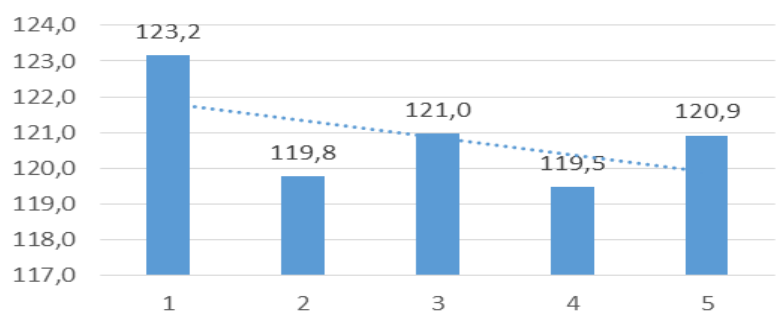

Em relação ao rendimento escolar, no modelo final de regressão verificou-se que os alunos com idade abaixo dos 21 anos, cujos pais apresentavam escolaridade até o ensino fundamental, que confiavam em si mesmo raramente ou nunca, e que apresentavam baixo nível de resiliência estiveram associados a uma pior autopercepção do rendimento escolar. Os resultados estão ilustrados na tabela 1.

Tabela 1. Análises brutas e ajustadas entre o Rendimento escolar (Regular/Ruim/Péssimo) com as variáveis independentes.

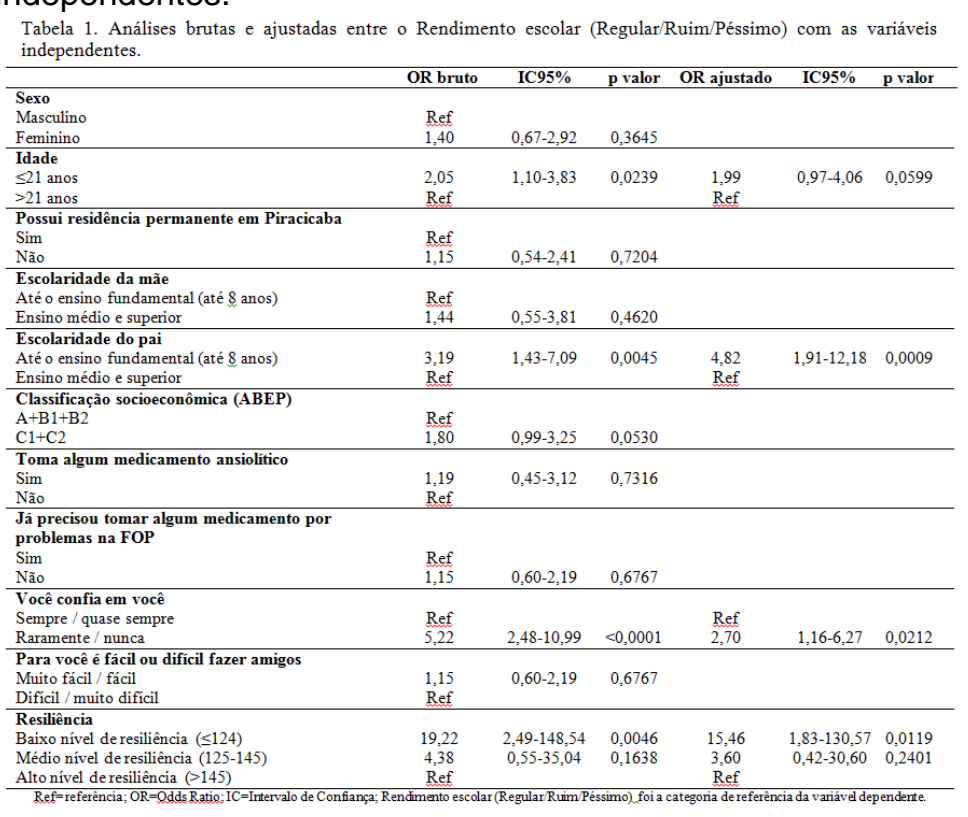

\section{Conclusões}

Observou-se pouca variabilidade no grau de empatia ao longo dos anos e que o rendimento escolar é influenciado por variáveis psicossociais. Ao longo da graduação, a diferença de escores médios por turma não é estatisticamente relevante, o que indica que esses indivíduos não divergem de maneira significativa em se tratando de questões empáticas.

Ao CNPq e à UNICAMP 